ASLI QoL 2017
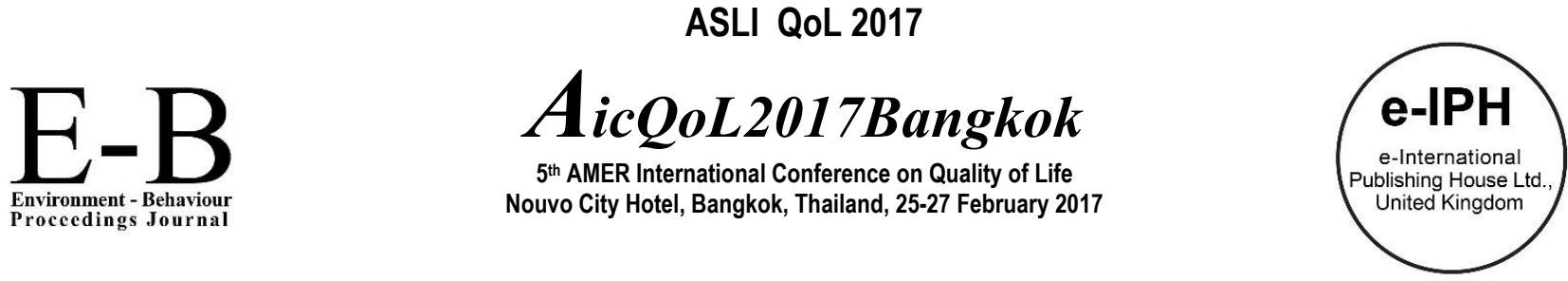

\title{
A Classification of Product Service System Concept in the Environmental Aspect to Create the Strategy of the Design of PSS
}

\author{
Ornwiriya Namsawat ${ }^{* 1}$, Yanin Rugwongwan ${ }^{2}$ \\ ${ }^{1}$ Arch.D. Student, Multidisciplinary Design Research Program, \\ Faculty of Architecture, King Mongkut's Institute of Technology Ladkrabang (KMITL), Thailand \\ ${ }^{2}$ Asst. Prof. Ph.D. program in a school of Interior Architecture, Faculty of Architecture, King Mongkut's Institute of Technology Ladkrabang (KMITL), Thailand
}

\begin{abstract}
Product Service System (PSS) is one of the procedures used to control the environmental problems arising from products and demand for product consumption. The method is aimed at creating a business system that sells products and boosts services for the maximum benefit of consumers. However, the PSS concept has many dimensions in the context of economy, society, and environment which are prioritized differently. This research is aimed at studying the literature review of PSS based on the environmental significance. The objective of this research is to analyze and classify the PSS factors in the environmental dimension and explain the factors affecting the creation of PSS strategy.
\end{abstract}

Keywords: Product Service System; Design for Environment; Product Service Design Strategies; Sustainable Consumption.

ISSN: 2398-4287@ 2017. The Authors. Published for AMER ABRA by e-International Publishing House, Ltd., UK. This is an open access article under the CC BYNC-ND license (http://creativecommons.org/licenses/by-nc-nd/4.0/). Peer-review under responsibility of AMER (Association of Malaysian Environment-Behaviour Researchers), ABRA (Association of Behavioural Researchers on Asians) and cE-Bs (Centre for Environment-Behaviour Studies), Faculty of Architecture, Planning \& Surveying, Universiti Teknologi MARA, Malaysia.

\subsection{Introduction}

At present, design for an environment is very crucial and taken into consideration to find the proper guidelines to design business Product. The negative effect might found from preparing raw materials, processing, distribution, transportation and short time of trendy furniture use (Besch, 2004). These cause the problems of dealing with disregarded furniture at the end of product life and consequently, an environment will be inevitably affected. Because of changing needs of consumers. The approach used as the guideline to control environmental problems and to carry out business strategies is called Product Service System or PSS. Via this method, selling goes in line with services so as to provide customers with the utmost benefits and services as they need. This PSS based on interaction system is under the product and service control and supervision of producers and stakeholders. Moreover, PSS is also applied to create the sustainable design in the aspects of environmental and resource responsibilities. However, the complete plan must be set out from the production stage to the end of product life. By doing this, PSS might be used to reduce negative environmental effect of business activities,

However, according to the literature review of the previous research, the PSS concept has many dimensions in the context of economy, society, and environment which are prioritized differently. To advertise the PSS concept beneficial to the knowledge and the creation of sustainable consumption pattern, this research is aimed at studying the literature review of the Product Service System (PSS) based on the environmental significance as a part of Sustainable Product Service Design Strategies of Business Furniture research. The objective of this research is to analyze and classify the PSS factors in the environmental dimension and explain the factors affecting the creation of PSS. The collection of the case study from the company puts the eco-friendly design approach in many procedures to practice through their products and services under the PSS concept.

\footnotetext{
${ }^{*}$ Corresponding author. Tel.:

E-mail address: onwiriya@gmail.com
}

ISSN: 2398-4287@ 2017. The Authors. Published for AMER ABRA by e-International Publishing House, Ltd., UK. This is an open access article under the CC BYNC-ND license (http://creativecommons. org/licenses/by-nc-nd/4.0). Peer-review under responsibility of AMER (Association of Malaysian Environment-Behaviour Researchers), ABRA (Association of Behavioural Researchers on Asians) and cE-Bs (Centre for Environment-Behaviour Studies), Faculty of Architecture, Planning \& Surveying, Universiti Teknologi MARA, Malaysia. DOI: http://dx.doi.org/10.21834/e-bpj.v2i5.663 


\subsection{Objective}

Analyzing the principle of PSS from the perspective of the environment effects to the making of the strategy by the method to design products and the method of service of the business system to be a part of the research of Design Strategies for Sustainable ProductService System of Furniture Business.

\subsection{Literature Review}

\subsection{Policy and guideline for sustainable development}

The policy and guideline for sustainable development are initiated by the government and business through creating strategies and various problem-solving methods for the environment to respond to the goal to solve the problem that is different from the industrial development with sustainability. In the beginning, the importance is for the production method to solve the problem of pollution and to solve the problem of the end stages of production such as waste minimization, and end of pipe solutions which are methods that deal with the management of environmental problems which lead to the short-term solution (Tim Cooper \& Evans, 2000). Later strategies by way of protecting methods are used such as cleaner production, and cleaner technologies which are methods that positively affect the industrial production process which helps to reduce the release of pollution and the creation of waste in the complete cycle of the production process-but some problems follow which are a result of modern technology causing mass production. The problem of power usage and the problem of products that are designed to have a short lifetime which become waste at the end of the product's life cycle are still hard to manage. Guidelines for product designs which are good for the environment or a design that emphasizes the product life cycle, therefore is a method that receives increasing interest from industrial manufacturers to be a policy for the responsibility of the environment through the design of products such as recycling approaches, eco-design, and design for sustainability. On the other hand, the strategic tool that is used in this operation of the environment still has the risk of creating environmental effects regarding consumption quantity that is increased by the consumption per unit of the products. Therefore, it is hard to cancel the connection between economic growth and the problem of using a quantity of resource that causes an effect to the environment because of the characteristics of modernity which stimulates a large amount of consumption for the purpose of economic growth. As a result, this time is to change the focus to the characteristics of sustainable consumption which is the next step for sustainable development that is a concept for collecting new things that are effective together in an organized way to stimulate the change of production system and consumption behavior by the service and combining products and services (Goedkoop, et.al.1999).Timeline of sustainable development approach (See fig.1).
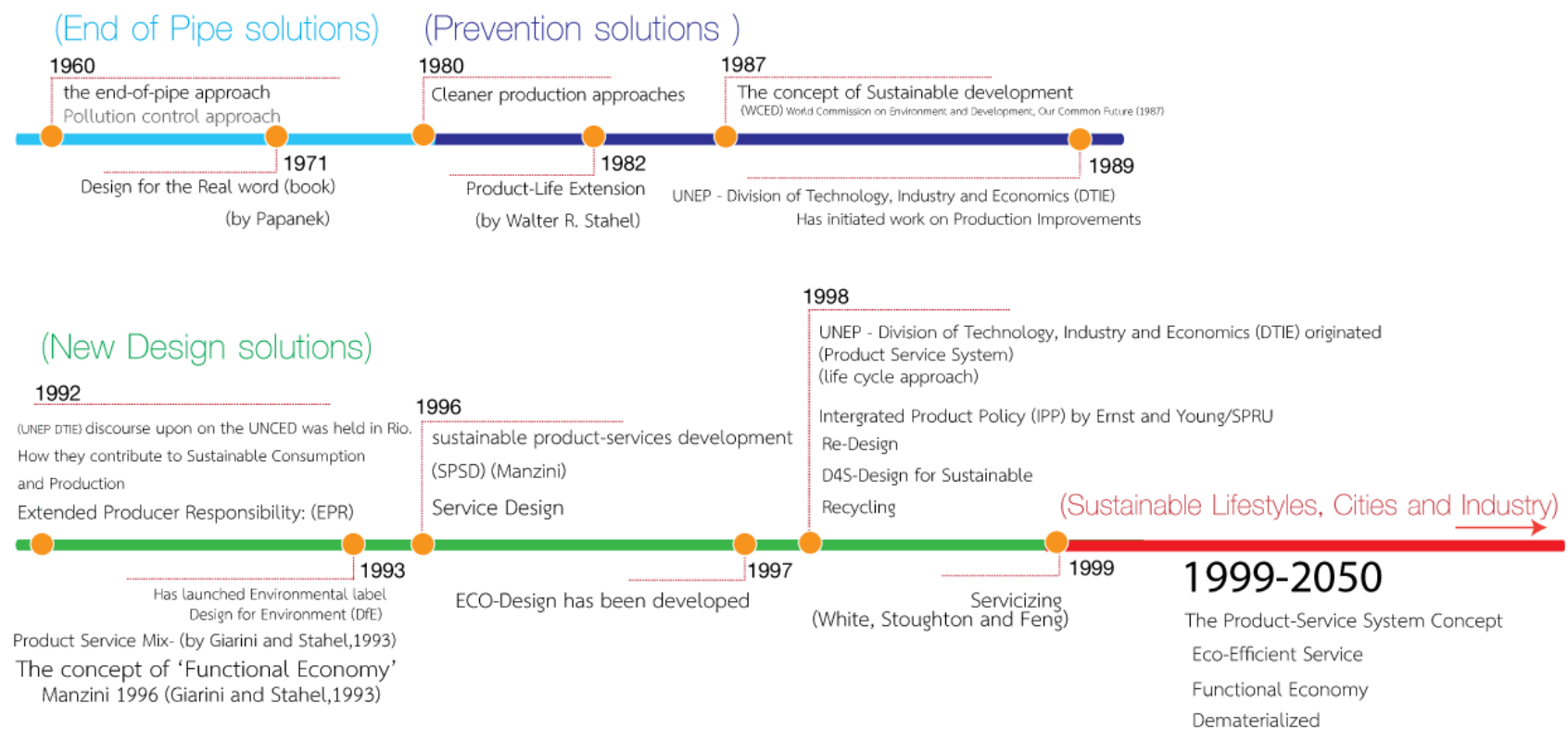

1989-1999 Many ways to be successful to reduced the environmental problem.

Fig. 1: Timeline of sustainable development approach

\subsection{Product Service System}

The concept of Product Service System (PSS) is one of the methods which is used to control the environmental problem resulted from products and the level of demand to consume the product. It is to create a business system for the sale of products and the service is added in which the beginning comes from the program of business marketing originated in the context of the industry in Europe. This concept of PSS is developed by Walter Stahel, and it is found that it is a method to run a business that can be applied to solve the characteristics of consumption and to use resources more effectively. The concept in the beginning stages of building the 
foundation of the development of the PSS concept is connected to the scope of the environment being a part of the closed-loop system, concept for reducing the use of resource (Dematerialization), product life extension, and service optimization strategies such as maintenance services, updates/upgrades services and remanufacturing (Stahel, 1982). Because the tendency of product design in the present is designed to have a short lifetime, the result is the problem of waste at the end of the lifetime of the products which is still difficult to solve. The direction of product design that is environmentally friendly or a design that is emphasized for product life cycle is increasing with more interest by industrial manufacturers to be used as a policy for environmental responsibility through the method of product design.

From revising of literature and research in the international level in the past, it is found that the change to the sustainable development must have the combination of the products and services which have an important role in modern times to provide services. These new services will stand out with low impact to the environment and have a high level of interaction from users. The development of the business may have the characteristic of leaping forward whereby the change must have a suitable product design that may have an integrated change in the combination of the product services. The present trend of products is based on product service which will mostly occur between the business market and the business (business to business). The operation for the environment is not the most important motivational reason for PSS to be used (Cooper, 2000)

\subsection{Principle of the concept of Product Service System (PSS)}

This research started from revising the literature theory in details for the development of the concept of PSS. After the analysis of researchers, it is found that there are various main issues for the detailed concept to create the principle of PSS (PSS concept).

Oksana (2004) conducted research relating to PSS to find and prove the matter to estimate the suitability of social institutes who developed a conceptual framework of the PSS principle for evaluation and development of the system for product service. This consists of 3-dimensional points of sustainable development by specifying four main factors of PSS and setting the goal of continuous development within the framework for evaluation and development. The PSS that is newly created expands the meaning of PSS to include institutional context, socio-cultural contexts, organizational layouts, and means of behavioral characteristics that are unique to the customer.

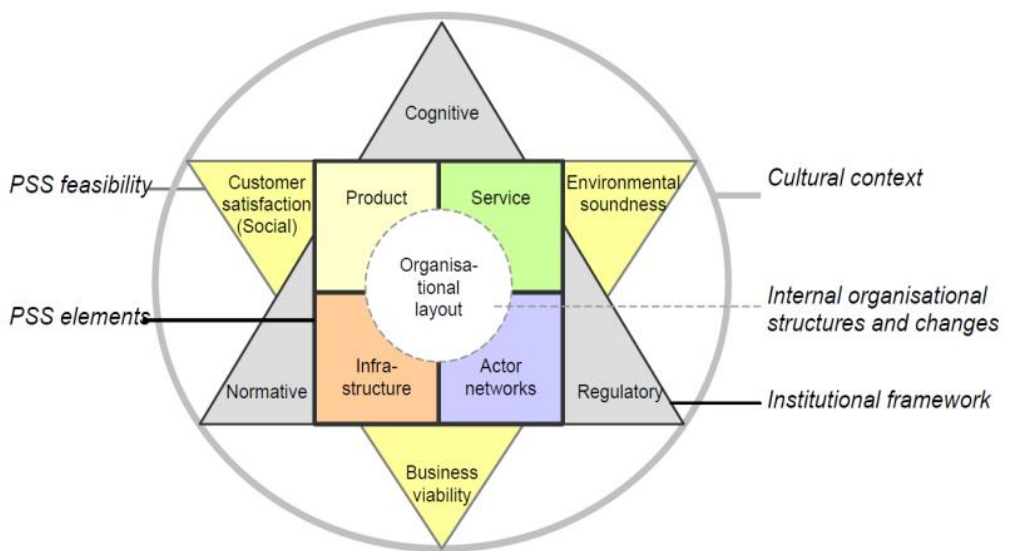

Fig. 2: the conceptual framework in the various dimensions of PSS (Source: Oksana, 2004)

On the other hand, the study of literature relating to the product service and service regarding eco-efficiency shows that the number of experts and academics who value the ideas from the environmental perspective or potential analysis of PSS for solving the problem to reduce the impact on the environment is small. PSS in this perspective is explained by the environmental academics. Manzini and Vezzoli (2003) said that the true characteristic of PSS which matches the idea of Tukker (2006) who informed that the environmental sustainable of the product-service will be strong by emphasizing the characteristic of choices to access the services by users (user-oriented services) and emphasizing the result (result-oriented services) which will create more sustainability for the environment than the approach which puts emphasis on the product (product-oriented service).

(Oksana, 2004) increased the response to the demand of the customer through service that is dematerialized which is likely to relate to the change of the status of the owners.

\subsection{Strategic concept in product designing method}

The proceeding of creating product design strategy in conjunction with services, PSS accounts for the overall impact on the environment or issues solving methods of product system in its life cycle, along with efficiency improvement and product design that result in the least impact on the environment. Researchers, therefore, have to consider building methods that incorporate strategies and organize service providing methods that result in lower environmental impact. The strategic incorporation could be done by dividing intensity of each method according to goals in each aspect of PSS principle, the environmental aspect. 


\subsubsection{Environmental friendly product design concept}

Product design that incorporate services contain similar attributes to Integrated Product Policy (IPP), but it is a strategy that focuses solely on the importance of product design. The objective is to allow for practical application and extend more toward environmental policy, covering throughout product life cycle, from raw material extraction to disposal. The importance of this core concept is the systematic viewing of a product, thus, allowing the designer to notify various impacts and issues throughout product life cycle. Ultimately, leading toward new designs which have lower environmental impact, creating new design methods and developments, developing a product that helps improve living standard as well as able to generate profit while limiting environmental impact. (Eenst\&Young/SPRU, 1998) The aim is to create a concept frame that only covers product and services system.

\subsection{Research Methodology}

To achieve research objectives, research procedure has been set consisting of 6 steps as follows.

1. Studies the theoretical concept of Product Service System method from literature reviews and past research works. Our review has identified 25 papers that are directly related to the topic of product service system. Also, studies of equipment, product and service designing methods that deliver environmental potential and promotes sustainable consumption. The aim is to analyze PSS principle in environmental aspect, leading towards PSS strategy formation of product businesses.

2. Carry out analysis determining the main concept of PSS principle, and analyze equipment use in product design and service design that leads toward PSS strategy formation of businesses

3. Construct equipment models of the designing method that able to solve objective issues according to PSS principle, in the environmental aspect that has been determined by analyzing product and service design methods base on a period interval of a life cycle of different products. In every activity of product's life cycle that relate to overall environmental impact, these activities should be considered and used in environmental method design. Thus, the researcher has divided overall product period into three different sections, namely, designing- usage- end of life period. This allows additional service activity to focus on particular product's life cycle sections that are the most essential and important when adding services into product system by considering PSS principle, on environmental aspect, which has been set to improve.

4. Construct PSS strategy model from the combination of designing methods base on set PSS principle criteria.

5. Screen to select 15 models from the constructed PSS strategy models with the aid of 3 professionals/ specialists. The models are evaluated via points given a base on set PSS principle criteria, in environmental aspect.

6. The researcher further develops the 15 selected PSS strategy models.

\subsection{Result and Discussion}

\subsection{Result:}

This research is aimed at studying the literature review of the Product Service System (PSS) based on the environmental significance as a part of Sustainable Product Service Design Strategies of Business Furniture research. The objective of this research is to analyze and classify the PSS factors in the environmental dimension and explain the factors affecting the creation of PSS. This research was conducted in three stage. First, we conducted the literature review. Second, we used secondary source (i.e., companies' websites, and case study of business strategy that there various approaches) to help develop our thinking to analyze and classify the PSS factors in the environmental dimension and collection of the product design strategies and Service optimization strategies. We will present our findings in the next sections. Four PSS principles from the perspective of the environment are illustrated in the table (See Table.1)

Table 1: Three PSS principles from the perspective of the environment are in the table

\section{Economical and social principle}

PSS creates the principle for the change in the growth of the economy regarding sustainable consumption. "A quality of life that is better by consuming fewer resources" (UNEP, 2015) goes together with economic growth and resource consumption that has less impact on the environment, which can be divided into the following points.

1.1) PSS is a concept to create change to the characteristics of the economy and society that is sustainable according to the idea of "a quality of life that is better by consuming fewer resources."

1.2) PSS is a concept to promote a characteristic of the economy that has less impact on the overall environment than the former economy.

1.3) PSS is a concept to bring the economy in the direction of "Functional Economy" which is an economy that specifies duties and is a method leading to practical, sustainable development. (Manzini, 2003)

\section{Environmental principle}

PSS creates the principle for the environment which has the purpose to reduce the quantity of resource consumption that affects the environment and uses natural resources for maximum effectiveness, which can be divided into the following points. 
2.1) PSS is a concept which promotes a lifestyle for consumption that is sustainable which may cause a change in the patterns of behavior and lifestyle.

2.2) The point which promotes sustainable consumption: This is the principle which reduces the use of resources and raw materials (Dematerialization).

2.3) PSS is the principle which has environmental potential from services (eco-efficient service).

2.4) From an environmentally friendly perspective, this is to reduce the effects to the environment.

\section{Business principle}

PSS creates the combining principles of products and services together with the network of the participants for the service and the supporters of the fundamental structural system which is a new characteristic for the benefit of businesses, which can be divided into the following points. products.

3.1) PSS is a method to increase the responsibility of the company and business to effect the environment with their

3.2) This is a new strategy that involves the participation of companies for integration which emphasizes combining various factors together.

\section{Customer responding principle.}

PSS is the principle that created from a combination of satisfactions that come from users' specific demands where they can be separated according to various points as follows:

4.1) It is a principle that promotes search of product usage demand of customers and meets customers' emotional satisfaction according to customer desire.

4.2) PSS is a principle that promotes a higher level of user's participation, which helps reduce environmental impact.

\subsection{A Classification PSS for environment.}

Our review has identified 25 papers that are directly related to the topic of product service system. These have been analysed, interpreted, and summarized. From this five key findings have been established.

Main PSS principle from environmental perspective:

1. Dematerialization

2. Effective use of products

3. Product-supporting services

4. Sustainable consuming behavior promotion

5. Manufacturer's responsibility

We separation the process. Of product of the life cycle 3 stage: Production, Use and Disposal and analyze the design strategy for environmental Created PSS strategy model from the combination of designing methods base on set PSS principle criteria and refers to the categorization suggested by Oksana (2004).

$$
\text { Environmental load }
$$

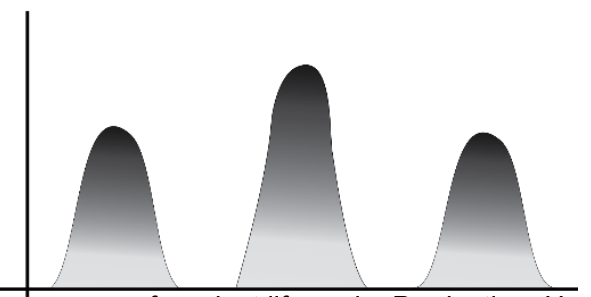

Fig2. threte range.efproduct life:cycle: Produgtion, Use and Disposal

Table 2. Product optimization strategies

\begin{tabular}{|c|c|c|c|c|}
\hline \multicolumn{5}{|c|}{ Product optimization strategies } \\
\hline design method & (Production) & (Use) & (Disposal) & Environmental Goals \\
\hline 1. material substitution & $\checkmark$ & & & (1) dematerialization \\
\hline 2. reduction of consumables & $\checkmark$ & & & (1) dematerialization \\
\hline 3. product life extension & & $\checkmark$ & & (2) effective use of products \\
\hline 4. design for disassembly & & $\checkmark$ & $\checkmark$ & (2) effective use of products \\
\hline 5. design for disposability & & & $\checkmark$ & (5) manufacturer's responsibility. \\
\hline 6. waste source reduction & $\checkmark$ & & & (4) sustainable consuming behavior promotion \\
\hline 7.toxic and waste product reduction & $\checkmark$ & $\checkmark$ & $\checkmark$ & (5) manufacturer's responsibility. \\
\hline 8. energy use reduction & $\checkmark$ & $\checkmark$ & & (4) sustainable consuming behavior promotion \\
\hline 9. modular design for upgrading & & $\checkmark$ & & (2) effective use of products \\
\hline 10. design for recyclability & & & $\checkmark$ & (5) manufacturer's responsibility \\
\hline 11. design for reusability & & & $\checkmark$ & (5) manufacturer's responsibility \\
\hline 12. design for easy repair & & $\checkmark$ & & (5) manufacturer's responsibility \\
\hline 13. design for integrate functions & & $\checkmark$ & & (2) effective use of products \\
\hline
\end{tabular}


Table 3. Service optimization strategies Service optimization strategies

\begin{tabular}{|c|c|c|c|c|}
\hline design method & (Production) & (Use) & (Disposal) & Environmental Goals \\
\hline $\begin{array}{l}\text { 1. Support services during design, } \\
\text { production of products }\end{array}$ & $\checkmark$ & & & (3) product-supporting services \\
\hline 2.Services at the point of sale & $\checkmark$ & & & (3) product-supporting services \\
\hline 3. Help Desk - hot line on product & & $\checkmark$ & & (3) product-supporting services \\
\hline 4. Various concepts of product use & $\checkmark$ & & & (3) product-supporting services \\
\hline 5. EOL services & & & $\checkmark$ & (3) product-supporting services \\
\hline 6. Updates/upgrades Services & & $\checkmark$ & & (3) product-supporting services \\
\hline 7. Spare parts and consumables Delivery & & $\checkmark$ & & (3) product-supporting services \\
\hline $\begin{array}{l}\text { 8. Leasing , Renting, Sharing and Pooling } \\
\text { services }\end{array}$ & $\checkmark$ & & & (3) product-supporting services \\
\hline 9. Support transportation & $\checkmark$ & & & (3) product-supporting services \\
\hline 10. Maintenance services & & $\checkmark$ & & (3) product-supporting services \\
\hline 11. Recycling and take back & & & $\checkmark$ & (3) product-supporting services \\
\hline 12. Extended warranty & & $\checkmark$ & & (3) product-supporting services \\
\hline 13. Financial services & $\checkmark$ & & & (3) product-supporting services \\
\hline
\end{tabular}

\subsection{Conclusion:}

To achieve the findings of this research, the researcher analyzed the PSS principle in relation to the environmental dimension to develop a PSS strategy to create a better quality of life. The PSS principle sets the vision that consumption can go side by side with an economy that consumes a small quantity of resources. It is an advanced level of concept of quality of life which aims at a sustainable society.

To demonstrate that the PSS principle can be translated into practice as a guideline to sustainability, the researcher elaborates the implementation of the PSS principle in 5 aspects which aim to diminish impacts on the environment. The PSS concept aims to transform consumption and production behaviors to bring about the opportunity for sustainable quality of life.

1. Dematerialization

Dematerialization reduces environmental problems through different means: for example, resources searching, product design which reduces material usage, usage of substitute materials, closed-loop system, promotion of the service which revives the products, recycling, reduction of the energy used in resource searching, production and transportation, and design which uses environmentalfriendly materials.

2. Effective use of products

It means a design which promotes product durability for long-term usage and the design of component assembly to facilitate repair or component upgrading. Two interesting furniture firms in the United States that sell their furniture product globally are Herman Miller Inc. and Steelcase Inc. Both firms are situated in the state of Michigan and have developed an environmental plan that shares the goal of eliminating and reducing environmental impact throughout the product's lifecycle, and especially on the issues of solving garbage and dangerous waste. Their work consists of a one-stop product care strategy, allowing for the product remains to be easily reused or reconditioned or disassembled and for components to be easily recycled.

3. Product-supporting services

Product-supporting service is the increase of benefits arising from the service to promote the efficient use of products: for example, the supportive service for the design, production and transportation, service at the selling shop, technical service, consultation service for customers regarding the products, and maintenance/repair/product-upgrading service.

4. Sustainable consumption behavior promotion

The PSS principle promotes a low quantity of resource usage for better quality of life and sustainable consumption: for example, reduction of consumption through various product usage such as leasing, sharing, pooling, and renting.

Oksana (2005) studied the PSS principle with regard to the environmental impact and found that the sharing usage can significantly reduce the impact on the environment through the extended life cycle of a product. The PSS principle emphasizes the use phase to reduce the impact on the environment arising from consumption. It reduces the ownership, and consequently possession. However, feasibility needs to be further studied, as developing countries still need to increase their domestic consumption levels for basic facilities.

5. Manufacturer's responsibility

There are an increasing number of business firms and industrial entrepreneurs that recognize environmental management issues, and it has been set as the main issue in business strategies. Thus, capable of a long-run business management policies. There are a possibility in the future that every firm must participate more or must implement various strategies to reduce environmental impact issues that cause by their own products and services. Government policies and laws have realized the importance on the rise of manufacturing and consumption, which lead toward subsequent environmental issues. The End-of-Life (EOL) method is applied to improve the end phase of the product's life span which will eventually promote the change at the stage of the product design. 
But the challenge of the PSS concept on the part of the manufacturing companies is that many companies are not willing to comply with this idea. If the PSS concept is applied together with an effective resource usage plan based on advanced technology, the company could make profit from recycling through cradle-to-cradle business. And this could be the business opportunity in the future.

The SPREAD project promotes material footprint measurement to achieve sustainable living in 2050. The consumption of a product made of various materials is a useful indicator to measure sustainable living (Bringezu et al., 2009). This is to enhance equal natural resource usage to maintain a balanced ecological system for new generations.

Breukers et al.(2011) clarified the possibility of sustainable usage of products and services for effective consumption (less resource loss), different consumption (products and services of higher quality) and adequate consumption (less materials).

The reduction of the environmental problems based on the above-mentioned principles will promote the efficient use of products and sustainable consumption behavior. The determination and development to enhance the competency of all interested manufacturers are essential in creating a lifestyle of low carbon emissions, the transformation to a sustainable society and the realization of quality of life.

The next step of this research is creation of modelling tool for product designing method that integrate services according to the goals of PSS principle, in environmental aspect, obtained from this research, by submitting to 3 product design professionals for scoring base on the criterion of PSS principle, in the environmental aspect, in order to further select 15 models. Others expectations relating to PSS are to have a capability in decreasing impact on the environment that relates to the creation of business offers that could provide appropriate use value, which will be the next step of this research development project.

\section{Acknowledgements}

I would like to express my sincere thanks to my dissertation advisor, Prof.Dr.Yanin Rugwongwan and Dr. Wichitra Singhirunnusorn, for invaluable help and constant encouragement throughout my research and the kindness in editing my English paper. Also, I would like to thank the Faculty of Architecture, King Mongkut's Institute of Technology Ladkrabang, all friends Multi - disciplinary program and those whose names are not mentioned here but have significantly inspired and encouraged me throughout this course.

\section{References}

Breukers, S.,et al. (2011). SPREAD Sustainable Lifestyles 2050. ECN, Lund University and CSCP, Wuppertal.

Bringezu, S. (2009). Visions of Sustainable Resource Use. In: Bringezu, S. Global Trends, Visions and Policies. Greenleaf Publishing, Sheffield.

Cooper,T.,\& Evans S. (2000). PRODUCTS TO SERVICES. A report for Friends of the Earth produced by, The Centre for Sustainable Consumption, Sheffield Hallam University

Goedkoop, M., Halen, C., Riele, H.,\& Rommens, P. (1999). Productservice systems, ecological and economic basics. The Netherlands: Pre consultants; [Online] Available from: http://www.pre.nl/pss/default.htm

Walter R. Stahel (1982). Chapter 4 - The Product-Life Factor. An Inquiry Into the Nature of Sustainable Societies: The Role of the Private Sector Edited by Susan Grinton Orr. Harc Houston area research center

Oksana, M. (2004). Product-service system: panacea or myth? PhD thesis.IIIEE,Lund University,Sweden.

Manzini, E., Vezzoli, C. (2003). A strategic design approach to develop sustainable product service systems: examples taken from the 'environmentally friendly innovation' Italian prize. Journal of Cleaner Production 11 (8), 851-857.

Brezet, JC., Bijma, A.S.,\& Ehrenfeld, J. (2001). The Design of Eco-Efficient Services; Method, Tools and Review of the Case Study Based 'Designing Eco-Efficient Services' Project. Ministry of VROM-Delft University of Technology.

Tukker, A., Tischner, U. (2006). New Business for Old Europe: Product-service Development, Competitiveness and Sustainability. Greenleaf Publishing, Sheffield.

Manzini, E., Vezzoli, C. (2003). A strategic design approach to develop sustainable product service systems: examples taken from the 'environmentally friendly innovation' Italian prize. Journal of Cleaner Production 11 (8), 851-857.

Glavi_c, P., Lukman, R. (2007). Review of sustainability terms and their definitions. Journal of Cleaner Production. 15 (18), 1875-1885.

Ernst\&Young/SPRU. (1998). for the European Commission Integrated Product Policy.Retrieved December 15 2015, from http://www.europa.eu.int/comm/environment/ipp/home.htm

Katrin Besch. (2004). Product Service Systems for Office Furniture Barriers and Opportunities on the European Market. International Institute for Industrial Environmental Economics (IIIEE), Lund University.Sweden

UNEP. (2015).Sustainable Consumption and Production Policies and Initiatives in Eastern Europe and the Caucasus: Review of Progress and Way Forward. Retrieved March 7, 2016, http://www.unep.org/roe/Portals/139/documents/SCPreport_lores\%20ENG.pdf 